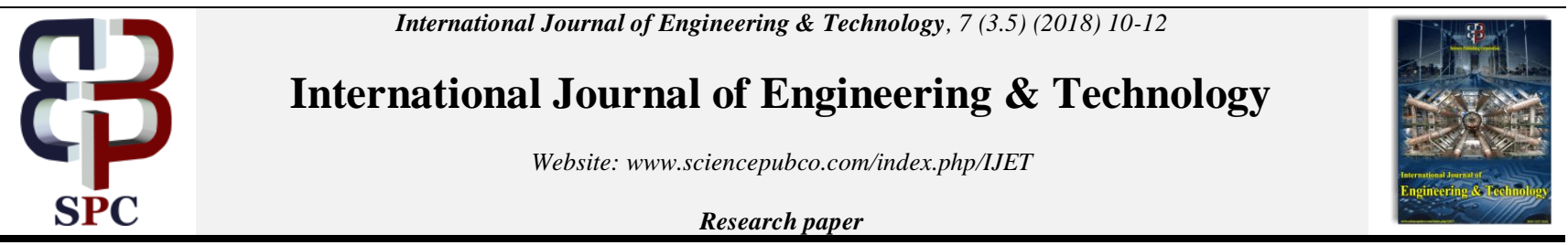

\title{
A 3D Design Based on Jewelery Production Technology with Special Features
}

\author{
E. S. Gamov *, S. B. Tonkovid *, V. A. Kukushkina *, N. A. Nikulcheva * \\ * Lipetsk State Technical University, Russia
}

\begin{abstract}
This article shows the process of development and manufacturing of the exclusive "Ring" product with application of modern technologies of its manufacturing. The main stages of the process of designing, modeling and getting the finished product are presents. Recommendations for the selection of software are given. The advantages of application of additive technologies in jewelry production are shown.
\end{abstract}

\section{Keywords:}

\section{Introduction}

In the world of innovative design technologies, much attention is paid to the use of high-tech processes of processing of materials. This is especially true for jewelry which has a complicated shape, individual characteristics of texture which give a unique effect of the surface of the product. The maximum realization of design ideas in jewelry production occurs through the using of additive processes. It allows us to realize complicated creative processes that aim not only at obtaining highly aesthetic works of design art, but also transferring certain information about modern fashion and style features. An example of a product in which such processes are realized is the exclusive gift product "Ring". It was manufactured using advanced technologies in the jewelry production field. The shape of the ring is strictly regulated by appropriate ergonomic norms. The study of process and conditions for the creation of such products will allow to find the optimal ways of its design, which contribute to the improvement of quality and the expansion of expressive means.

\section{Research Method}

The study was carried out using the modeling method, taking into account the experimental data previously obtained by the authors in university conditions [1-5].

At the first stage, a sketch of the product was developed, as well as a choice of technology and materials for the implementation of creative design. During the work on the search for the shape of the future product, sketches were made (pic. 1). The author's plan is to develop and modeling a ring surface in which the elevation angle, scale, proportions and all the ratios of the metal thicknesses form an integral harmonious composition.

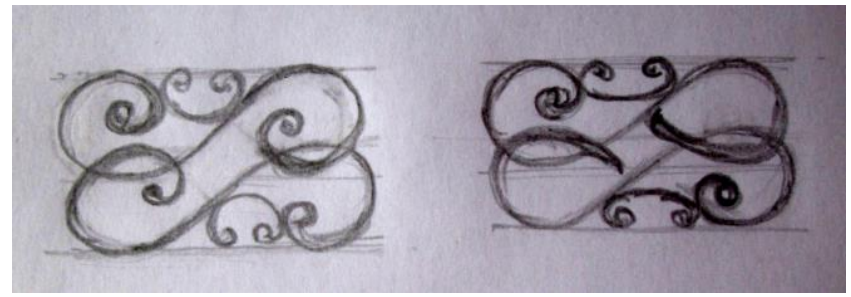

Pic. 1. Sketch of the product "ring"

At the second stage 3D modeling carried out in the program 3Design Cad Pro V5. The program allows you to make the process of creating a jewelry product less time-consuming and more effective. The general view of the program is shown on the picture 2 .

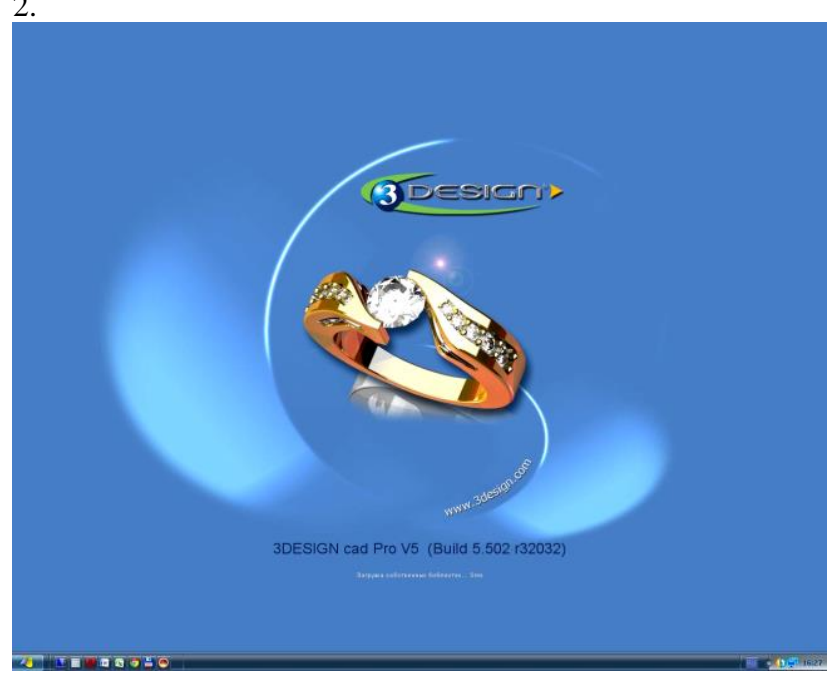

Pic. 2. The general view of the program 3Design Cad Pro V5

This program created by French developers especially for jewelers. This program can simulate a product of any complexity and make its layout if you having chosen the necessary complex of materials, and visually to get any viewing angle, taking into account the color, texture and lighting conditions. The program is equipped with functions and elements that simplify the process of 
creating a jewelry product. As a result, the elements of the 3D model were developed (pic. 3).

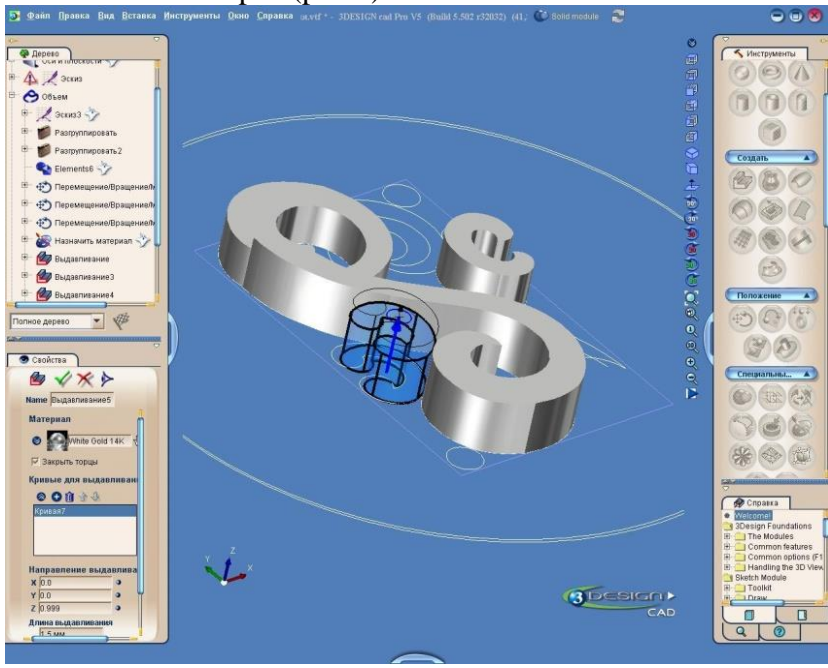

Pic.3. The process "pressing". Obtaining a figure with parameters N 1,2

The resulting file of polygon model was converted to stl format and then sent to print in a 3D printer brand Soliscape T66, which "grew" a wax model with supporting structures (pic. 4)

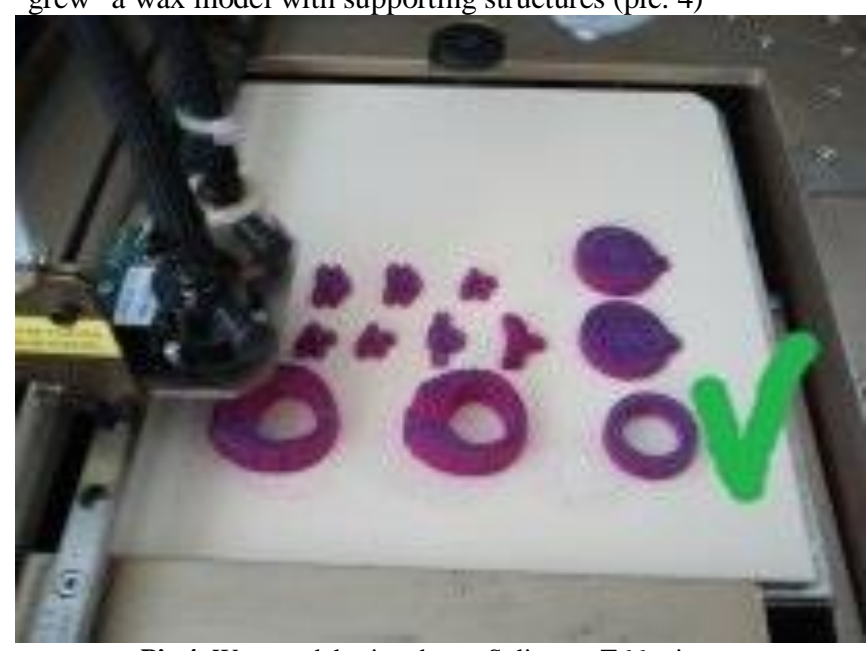

Pic.4. Wax model printed on a Soliscape T66 printer

Then the following operations were carried out:

1. Removing the wax model from the base surface.

2. Putting it in a special solute to delete the supporting structure.

3. Extraction of the wax model from the solute for the subsequent of the product in the material. The resulting wax model predetermined the method of obtaining the finished product. He became the method of investment casting. Its core is expressed in the technological sequence:

The resulting wax model of the product was connected to a pre-prepared wax model of the main casting channel-riser, as a resuls is a wax-shaped "herringbone", which was placed on a rubber base. The resulting model unit is installed in a flask (stainless steel vessel with a rubber pallet), and the wax block is then poured with a molding compound (slurry containing refractory aggregate and water);

The molding mixture is compacted by the evacuation process on a vibrating table. At the same time, the suspension clamped and hardened;

The cured mass after drying in a flask was placed in a muffle furnace at a temperature of $2000^{\circ} \mathrm{C}$ to melt the model, after which it was made burning hot in an oven at a temperature of $7000^{\circ} \mathrm{C}$ for 8 hours. At the same time, wax residues are burned, degassing of the mold and its compaction are occurs;

Then the mold was removed from the cooling furnace;

After cooling, the casting mold was filled with liquid metal onto the "Vacuum-metal" installation.
4. The next operation - cleaning the casting from the molding mass.

5. Mechanical separation of the product from the cleaned block. The product was cleaned chemically in aqueous solutions of alkali. After that, the product was grinded and polished.

\section{Results and Analysis}

A comparative analysis shows that the manufactured jewelery "Ring" (pic.5) has not only high aesthetic and ergonomic characteristics, but also has medicinal properties, since its material is silver. It is known to be in contact with the human body, it has a healing effect: it has antimicrobial properties.

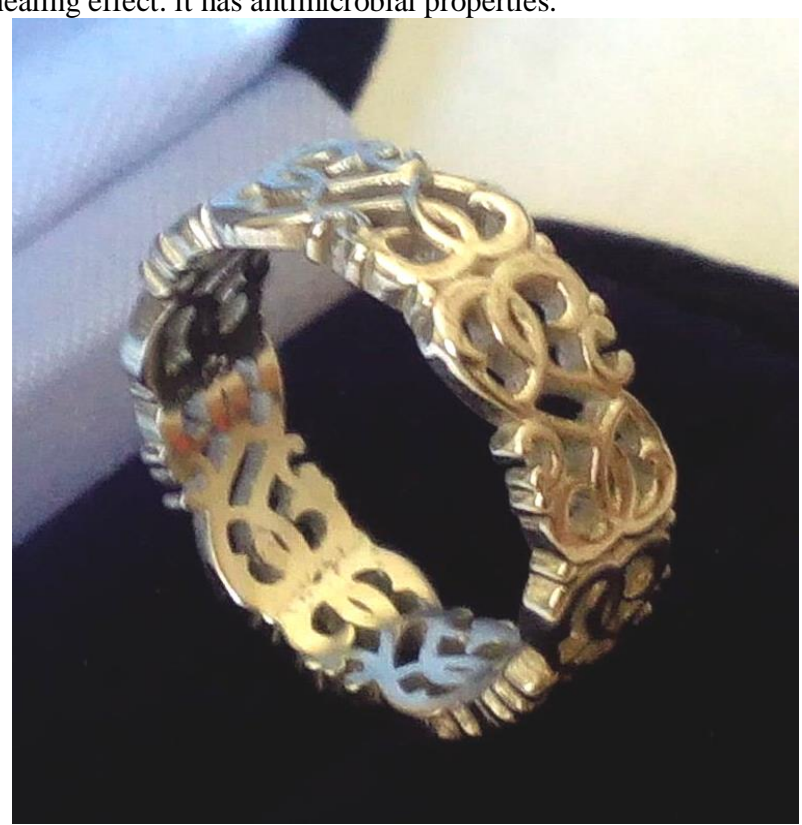

Pic.5. Ready product

High aesthetic and therapeutic characteristics of the resulting product confirm the relevance and prospects of using 3D technologies in industrial design for the manufacture of jewelry for various purposes. Additive technologies allow directly to make jewelry of almost unlimited complexity and, therefore, significantly expand the field of possibilities for artistic shaping. 3D modeling provides high quality jewelry, which increases their relevance, as well as turns individual works of artistic creativity into a mass production manufacturing.

\section{Conclusion}

As a result of the research, the main advantages of using 3D modeling are practically confirmed $[6,7]$ for jewelry production:

- more accurate design for a given size;

- significant time savings;

- simplification of the process of creating a model;

- calculation of the weight of the future product.

It has been practically established that the feature of additive technology is the application of supporting structures - supports. They are built during the printing of the product to support the overhanging elements, i. e. the creation of a physical object occurs by the method of synthesis (buildup) of a composite material based on a virtual model (CAD).

\section{References}

[1] Gamov E. S., Kukushkina V.A, (2018), Application of additive (digital) technologies for the manufacture of foundry artistic products, Foundry of Russia, No. 4, pp. 20-25.

[2] Gamov E. S., Kukushkina V. A, (2018), Theoretical and technological prerequisites for additive (digital) methods of foundry, Foundry of Russia, No. 3, pp. 28-38. 
[3] Tonkovid O., Tonkovid S. B, (2017), Progressive Technologies in Industrial Design, School of Young Scientists. Materials of the regional profile seminar on the problems of technical sciences. Publishing house of the Lipetsk State Technical University, pp. 139141

[4] Bashkevich Yu. A., Tonkovid S. B, (2017), 3D technologies in design, Trends in the development of modern science. Sat. Theses of the reports of the scientific conference of students and postgraduates of the Lipetsk State Technical University: in 2 parts, pp. 87-89.

[5] Tonkovid S. B., Smetannikova T. A., Konovalova A. P, (2016), The role and importance of 3D technologies in the development of creativity, Development of personal creativity in modern educational space. Sat. materials of the interregional scientific and practical conference with international participation, Publisher: Yelets State University named after. I.A. Bunina (Yelets), pp. 94-99.

[6] Gudelaitis A. K., Zhukova L. T, (2013), Manufacturing of jewelry by the method of three-dimensional modeling using modern hightech material processing processes, Design. Materials. Technology, No. 2 (27), p. 66.

[7] Kanessa E., Fonda K, (2013), Available 3D print for science, education and sustainable development, E. Kanessa, K. Fonda and other, Trieste: International Center for Theoretical Physics by Abdus Salam, p. 192. 